\title{
Solar Desalination by Humidification-Dehumidification of Air
}

\author{
J.Moumouh $^{1}$, M.Tahiri ${ }^{1}$, L.Balli ${ }^{1}$ \\ ${ }^{1}$ Mohammadia School of Engineering, Mohammed V University-Agdal, Rabat, Morocco
}

\begin{abstract}
The importance of supplying potable water can hardly be overstressed. In many arid zones, coastal or inlands, seawater or brackish water desalination may be the only solution to the shortage of fresh water. The process based on humidification-dehumidification of air $(\mathrm{HDH})$ principle mimic the natural water cycle. $\mathrm{HDH}$ technique has been subjected to many studies in recent years due to the low temperature, renewable energy use, simplicity, low cost installation and operation. An experimental test set-up has been fabricated and assembled. The prototype equipped with appropriate measuring and controlling devices. Detailed experiments have been carried out at various operating conditions. The heat and mass transfer coefficients have been obtained experimentally. The results of the investigation have shown that the system productivity increases with the increase in the mass flow rate of water through the unit. Water temperature at condenser exit increases linearly with water temperature at humidifier inlet and it decreases as water flow rate increases. HDH desalination systems realised on also work at atmospheric pressure; hence they do not need mechanical energy except for circulation pumps and fans. These kinds of systems are suitable for developing countries. The system is modular, it is possible to increase productivity with additional solar collectors and additional HDH cycles.
\end{abstract}

\section{Introduction}

The continued growth of demand for water and increasing shortage of supplies are two of the most certain and predictable scenarios of the 21 st century. Population growth is threatening the availability of fresh water in many regions of the world.

Over a billion people do not have access to safe supply of water and the number is growing. Large areas of the world already suffer from drought while deserts and populations increase in size. Rainfall remains broadly constant, yet demand for water has doubled in the last 20 years. As demand outstrips renewable supply, the depletion of ground water is accelerated [1].

Over the last three decades, of available brackish sources and/or seawater has been used to supply potable water resources in arid and semi-arid regions, as well as islands with limited storage capacity. Typical examples in the Mediterranean are Morocco, Egypt and Israel. The standard methods of desalination such as multi-stage flash evaporation and multi-effect evaporation, vapour compression and reverse osmosis are reliable in the range of some100-500,000 m3/d fresh water production.

They are not used in regions with a poor infrastructure either for the supply in decentralized regions due to their permanent need of qualified maintenance and electricity supply. Smaller scale, decentralized solar desalination a system is desirable and makes economic sense. The present desalination system shall fill this gap [2].

\section{Principle of the HDH Process}

The HDH process is based on the fact that air can be mixed with quantities of vapor. Air ability to carry water vapor increases by increasing its temperature. For example, $1 \mathrm{~kg}$ of dry air can carry $0.5 \mathrm{~kg}$ of vapor and about $(2814 \mathrm{~kJ})$ when its temperature increases from $30^{\circ}$ to $80^{\circ}$ as reported in Ref. [3]. When air flow is in contact with salt water, air extracts a certain quantity of vapor at the expense of the sensible heat of salt water (providing cooling). On the other hand, the distilled water is recovered by maintaining humid air at contact with cooling surface, causing the condensation of a part of the vapor mixed with the air. The condensation occurs in another heat exchanger in which salt water is preheated by latent heat recovery.

The HDH process operates, as any distillation process, with only one cross of salt water (once through). It can also operate with water recirculation. In the first case, the evaporation of $1 \mathrm{~kg}$ of water causes a decrease of about $60^{\circ} \mathrm{C}$ in $10 \mathrm{~kg}$ of salt water. The amount of recovered distilled water varies from $5 \%$ to $20 \%$ of the 
quantity of salt water in circulation. This leads to a very low concentration of the salt water but a high sensitive heat loss. In the second case, more concentrated solution and lower energy consumption are obtained [4].

\subsection{Description of the physical model of $\mathrm{HDH}$ open air-open water, Water heated}

Salt water enters the system at the dehumidifier and is used to cool and dehumidify a hot, humidified air stream. Salt water gets preheated as the enthalpy of vaporization is transferred to it from the moist air (condensation process). The condensate is removed as product water and the salt water is then further heated in a solar collector or water heater before it enters the humidifier. The hot salt water is used to humidify a colder air stream, so mass and heat are transferred from the hot salt water to the moist air stream (evaporation process) and the remaining salt water is extracted as brine. The air stream circulates continuously in an open loop (fig.1) [5].

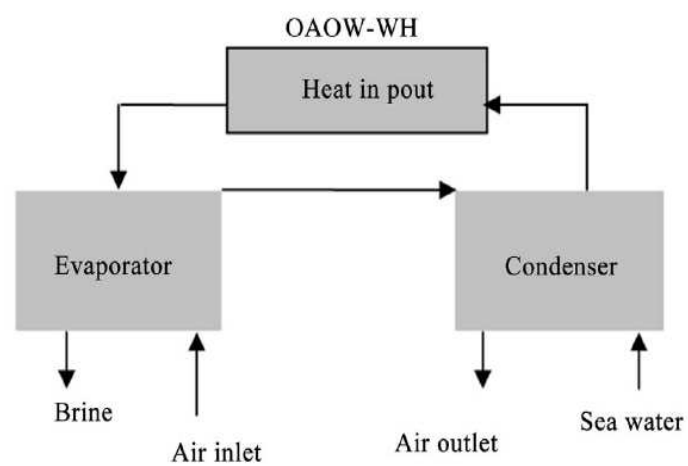

Fig. 1. Open air open water air-heated (OAOW-WH) system.

\section{Experimental details}

The purpose of this work is to verify experimentally the saltwater desalination process humidificationdehumidification of the air and to determine the effectiveness of this configuration. In fact, the experimental work was performed on a prototype installed in laboratry in Mohammadia School of engineering used to simulate experimentally the desalination process [6].

Fig.2 shows an image of the equipment before installing the thermal insulation. The condensation tower occupies is one compartment of the desalination unit.

The dimensions of the condensation tower are $72 \mathrm{~cm}$ height, $33 \mathrm{~cm}$ length, and $33 \mathrm{~cm}$ width. A copper tube coil is used in the condenser it as $50 \mathrm{~m}$ length and 1.27 $\mathrm{cm}$ outer diameter.
The other compartment of the desalination unit is the humidifying tower. Its dimensions are $170 \mathrm{~cm}$ height, 33 $\mathrm{cm}$ length, and $30 \mathrm{~cm}$ width. A packing material is fixed inside the humidifier; the specific area of packing material is $200 \mathrm{~m}^{2} / \mathrm{m}^{3}$. The water is sprayed on the packing material using a hydraulic grid.

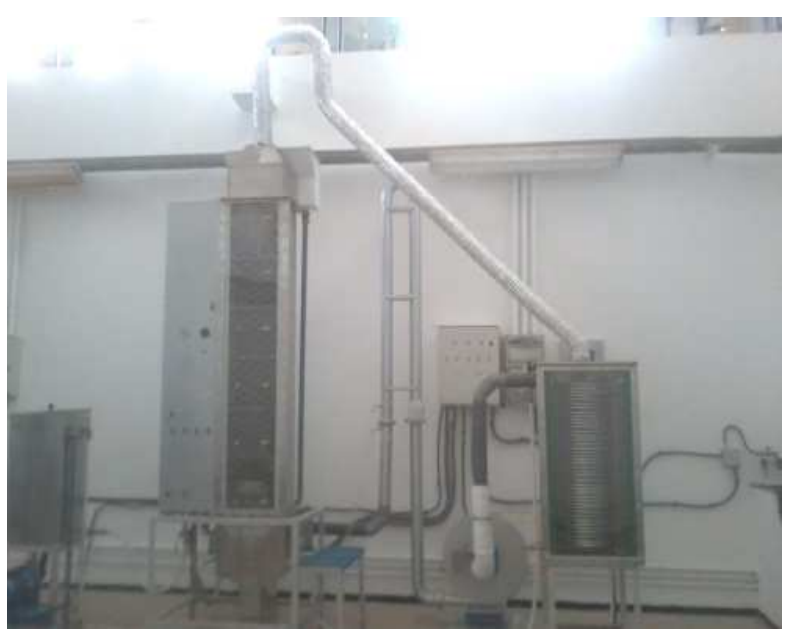

Fig. 2. Desalination prototype by Humidification

Dehumidification of Air.

A 200watts electric fan is used to blow the air through the unit. The fan is supported at the bottom of the tower. Water circulates by 500 watts centrifugal pump. A filter is used in the suction side to separate any impurities coming from the elevated tank water feeding.

A flow meter is connected on the delivery side of the pump to measure the water flow rate. A group of isolating valves are used to separate each part of the saline water loop from the system when necessary.

The external heat is provided via two electrical resistances 2400 watts that can be used to simulate the solar input during a day, and the actual heat input is monitored via voltage and amperage. Temperatures of air are measured with wet thermometers. The air flow is measured by Extech digital anemometer. The rate of distillate is measured with a $1000 \mathrm{ml}$ graduated test tube and a chronometer.

\section{Results and Discussion}

The variation of the distillate production with temperature in two different air flow rate is shown in fig.3. The amount of water production increases with increases in air flow rate.

The airflow rate increases, the productivity is increased at $\mathrm{T}_{\mathrm{w}}=60,70$ and $80{ }^{\circ} \mathrm{C}$ except for $\mathrm{T}_{\mathrm{w}}=50^{\circ} \mathrm{C}$ is decreased. This is due to the increase in the diameter and the density distribution and kinetic energy of air bubbles in hot water layer. 


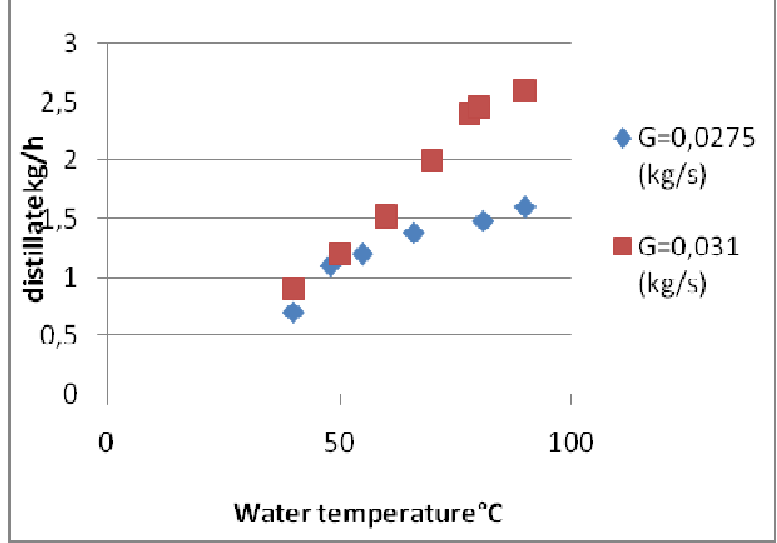

Fig. 3.Effect of flow air in distillate production.

The effect of water and air temperature on the productivity of the system is shown in Fig .4. The distillate flow rate increases with the increase of water temperature in evaporator chamber on the productivity of the system at $\mathrm{Tw}=45,50,60$ and $70{ }^{\circ} \mathrm{C}$.

It found that the humidity of air increases appreciably, with the temperature of water at the inlet of the tower. The rate of distilled water varies linearly as a function of the air temperature at the humidifier outlet. This means that the increase of the hot water temperature at the entrance of the evaporation tower produces more heat inside the installation.

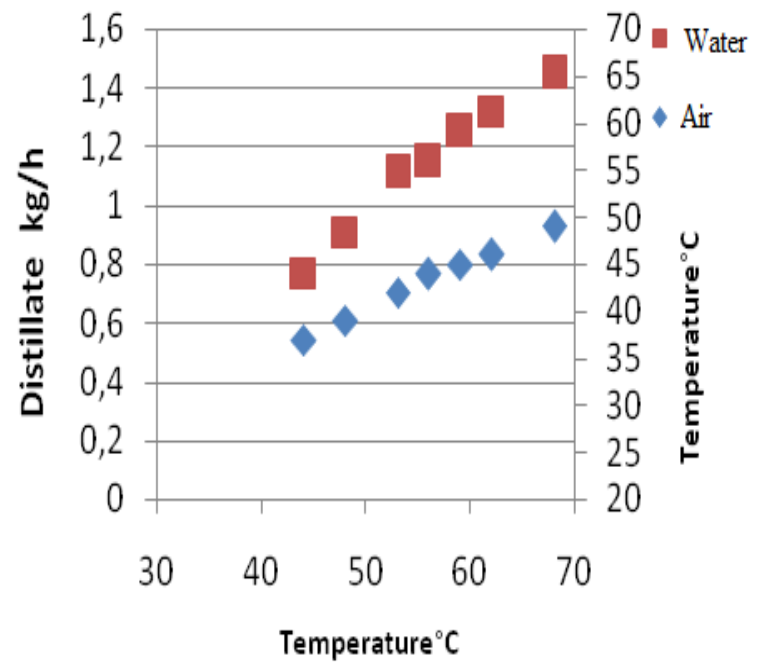

Fig.4. Distillate Evolution in function of $\mathrm{T}_{\text {winth }}, \mathrm{T}_{\text {aouth }}$

Growing branch of the curve of variation of the water content of the air in function of the flow ratio is illustrated in Fig .5 .shows that the power to evaporation of the water increases by increasing the amount of water in the humidifier, it is similar to the literature in Ref. [7].

This implies that the heat conveyed is still sufficient to allow the exchange of heat and material between the water and air throughout this branch. Decreasing branch of the curve shown in Fig.5, shows that the vapor diffusion of water in air decreases with increasing amount of water in the humidifier, this implies that the heat conveyed by air decreases also.
Decreasing the air transfer of heat to the water is due to the decrease of the air-water mixture temperature by increasing the amount of water in the humidifier.

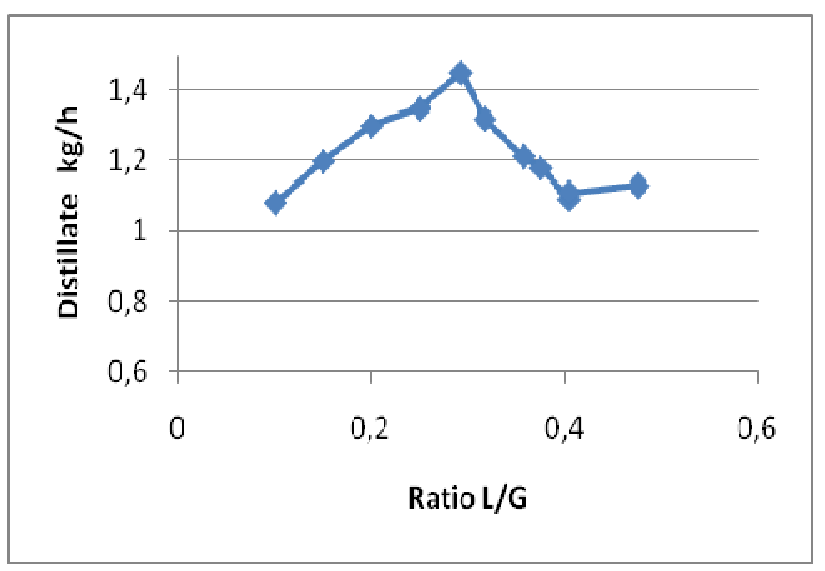

Fig. 5. Variation of production rate in function of water flow rate.

Fig. 5. indicates the variation of the quantity with the change of the normalized mass flow rate of the saltwater. It shows that there exists an optimum mass flow rate ratio corresponding to a maximum flesh water production.

\section{Conclusion}

The present work concerns an experimental study of a water desalination system. The system based on the humidification-dehumidification principle is a modular one and has the following independent components: water heater, an evaporator and a condenser. Some experimental results are analysed. They show the evolutions of water productivity in function of the temperature of air and water and the mass flow rate of water and air at the inlet and the outlet of each component of the system. The results show that there exists an optimum mass flow rate ratio corresponding to a maximum fresh water product.

\section{References}

1. Karim Bourouni et al.water humidification dehumidification of air, Solar Energy Conversion,(2103).

2. A. M. A. Dayem et M. Fatouh. Experimental and numerical investigation of humidificationdehumidification solar water desalination systems ,DES 247, 594-609, (2009).

3. A. E. Kabeel, M. H. Hamed, Z. M. Omara, et S. W. Sharshir, Water Desalination ,DES, 286-305, (2013).

4. D. D. E. E. Geográfica, G. E. Energia, F. Diogo, A. Santos, et M. Azevedo, Renewable Energy Powered Desalination Systems: Technologies and Market Analysis Renewable Energy Powered Desalination Systems : Technologies and Market Analysis, (2014). 
5. Prakash G, Narayan, Sharqawy MH, Summers EK, John H. The potential of solar-driven humidificationdehumidification desalination for small-scale decentralized water production.Desalination;( 2010).

6. J.Moumouh et al. Theoretical and experimental study of a solar desalination unit based on humidificationedehumidification of air. IJHE 41, 20818-822, (2016)

\section{Nomenclature}

G $\quad[\mathrm{kg} / \mathrm{s}] \quad$ Air flow rate
$L \quad[\mathrm{~kg} / \mathrm{s}] \quad$ Water flow rate
$T \quad[\mathrm{C}] \quad$ Temperature

\section{Subscripts}

$\mathrm{HDH}$

$w$

$a$

outh

inth

WH
Humidification, dehumidification water

air

External of humidifier

Internal of humidifier

Water heater 